\title{
Desk of the Editor Vol.6 Issue 1
}

\author{
K. S. Gopinath
}

Published online: 20 February 2015

(C) Indian Association of Surgical Oncology 2015

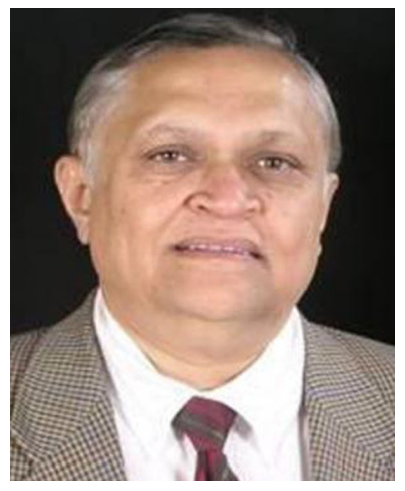

Cancer is a major public health problem across the globe. The nature of cancer, survival, mortality and epidemiological data differs in various parts of the world. This issue we have brought out on of pancreatic malignancies, the various treatment modalities as a standard of care.

Incidence:

232,000 new cases diagnosed worldwide each year. $61 \%$ occur in developed countries ranks 13th in terms of most common cancers. Mortality: 227,000 deaths from pancreatic cancer worldwide each year, ranks 8th in terms of most common causes of cancer death. Mortality / incidence ration

K. S. Gopinath $(\bowtie)$

HCG - Bangalore Institiute of Oncology,

Bengaluru, Karnataka 560027, India

e-mail: gopiijso@gmail.com

\section{K. S. Gopinath}

Sri Devaraj Urs Medical College, Kolar. No. 20, Srinivasa Behind

Balaji Kalyana Mantapam, BSK III Stage, Bangalore 560085, India
$(\mathrm{M} / \mathrm{I})=98 \%$. (Parkin DM et al., CA - Cancer J Cli 2005; 55: 74-108)

The incidence of pancreatic cancer in India is low (0.5-2.4 per 100,000 men and $0.2-1.8$ per 100,000 women.) The incidence of pancreatic cancer is higher in the urban male populations of western and northern parts of India but time trends show that this figure is increasing for both carcinoma of the pancreas and also periampullary tumors.

The annual pancreatic cancer load in India in 2001 was approximately 14,230 patients: the estimated current figure is approximately 17,000 and is likely to increase in the near future. The situation calls for the need of multicentre studies, more systematic approach to documentation at all levels and the need to identify potentially preventable risk factors associated with pancreatic cancer in India.

The southern part of the India an entity of tropical pancreatis is well described. The Puneeth Dhar et all have highlighted the concept of Pancreatic cancer and pancreatitis. The concept of Neoadjuvant therapy, adjuvant and palliative care chemotherapy is highlighted.

Prevention of complications of following pancreatic surgery is discussed. The emerging role of minimal invasive surgery including whipples procedure a review and institutional experiences as well document.

I really thanks Dr.Chandra Are accepting our invitation to be the guest editor and carefully, scrutinizing reviewing all the articles very methodically, to help the readers to acquire knowledge.

I thank all the authors, reviewers who had responded to our invitation and submitting their experiences.

I congratulate Prof.K.Harish, Associate Editor (M.S.Ramaiah, Medical College, Bangalore), reselected to the office and thank him for his support. I thank IJSO office staff Dr.Shivananada Swamy (Ambuja Health Care), 
Mr.J.Suresha (Dayananda Sagar Institutions), Bangalore, and also Springer team Dr Naren Aggarwal Executive Editor Clinical Medicine, (Mr.) Kenneth Xavier U. Mercullo, Journals Production, Mr. Ashok Kumar, Executive - Editorial Support Publishing and Lorelie Protacio (Ms), Journal's Editorial Office (JEO), JEO Assistant
Now we are in the sixth year of publication, expecting a constructive criticism to bring new change in the methodology of publications.

With regards,

Dr.K.S.Gopinath

Chairman/ Editor IJSO 